\title{
Investigation of the Mechanical Properties of Cherry Fruit (Prunus Cerasus L.) in Order to Achieve Optimum Height of Fruit Storage Box
}

\author{
Sina Sharifi-Sangdeh* and Mohammad Hossein Aghkhani \\ Department of Mechanical Engineering Biosystem, Ferdowsi University of Mashhad, Iran
}

Submission: April 15, 2018; Published: June 15, 2018

"Corresponding author: Sina Sharifi Sangdeh (Master student of Agricultural Mechanization), Department of biosystem engineering, Ferdowsi University of Mashhad, Iran, Email: sharifi.sina@mail.um.ac.ir

\section{Introduction}

Sour Cherry (Prunus Cerasus L.) has a native fruit tree in Southwest Asia and Europe, as well as sour tart, and it's red. Its tree height is 3 to 10 meters. One hundred grams of cherry contains 16 grams of sugar, 0.85 grams of protein and 8.6 calories, about 50 milligrams K, 20 milligrams of phosphorus, 1 milligram of iron, 400 international units of vitamin A, 0.14 milligrams of thiamine, 0.12 milligrams of riboflavin, $5 \mathrm{mg}$ of vitamin $\mathrm{C}$, as well as some potassium, sodium, magnesium, zinc, copper, and other minerals [2]. Neglecting the properties of agricultural products, will reduce both quantitative and qualitative losses, and the shelf-life of the products will not be possible. One of such biological characteristic of agricultural products is their susceptibility to damage and injury. Damage and injury among agricultural products are more likely to occur during harvesting, transport, sorting, and the meaty part of the products affected by repeated forces, lose their strength, and become softer and weaker, and thus corrupted. Corrupt products will endanger the health of neighboring products during long-term storage in the warehouse. Therefore, measures that reduce the mechanical damage to products have economic significance [1]. During the storage period for transport, the tension forces created between the products can cause the product to be damaged at the point of contact. Fruits transported with the box are affected by static and dynamic forces, and if the amount of these forces exceeds a certain limit, it can cause damage to them. Static forces are due to their weight and dynamic forces are due to vibrations generated by transportation. Consequently, due to severe fruit vulnerability, it should be packed in shallow boxes. Therefore, the aim of this study was to determine the appropriate depth of transportation and storage of cherry fruit.

The proper static pressure in order to select the height and depth of the transport box in planning the harvest and postharvest operations to prevent the damage to the various types of fruits, is of great importance. In general, the methods of reducing the mechanical forces involved in agricultural production can be divided into three main categories:

i. The design of the components of the machine for each work must be done in such a way that the forces involved attain to the minimum.

ii. Modification of the types of products that can tolerate larger forces without any mechanical damage.

iii. Harvest and post-harvest operations should be done when the mechanical strength of the product is sufficient to minimize the sensitivity to damage [1].

Research on peach fruit showed that the maximum tolerable static force without any mechanical damage to this fruit was about $15(\mathrm{~N})$. This force is equivalent to a column of fruit up to a height of $70 \mathrm{~cm} \mathrm{[1].} \mathrm{Also,} \mathrm{the} \mathrm{maximum} \mathrm{static} \mathrm{strength} \mathrm{for}$ apricot fruits in initial moisture was $27.82 \%$ based on $66.5(\mathrm{~N})$ [4]. The corresponding value for olive fruit in $60 \%$ moisture was determined as $57.38(\mathrm{~N})$ [5]. In another research, the length, width, thickness, geometric mean diameter for cherry fruit were 20.37( $\mathrm{mm}), 16.2(\mathrm{~mm}), 15.1(\mathrm{~mm}), 17.06(\mathrm{~mm})$, and the breaking force was determined $2.48(\mathrm{~N})$ which was approximately equal to 60 layers of fruit [3].

\section{Materials and Methods}

In this study, in year $96.5 \mathrm{~kg}$ of cherry fruit were prepared randomly from Rezvanshahr city, carefully cleaned and damaged fruits were separated from the specimens, and then the samples were weighed. The initial moisture content of the fruit (MC) was determined using an oven in a standard method at $75{ }^{\circ} \mathrm{C}$ until the fruit completely lost its moisture [4]. The initial moisture content was determined $13.77 \%$ on the basis of wet. The required parameters of the fruit for the calculation included length, width, height, geometric mean diameter, sample mass, fruit density and 
hardness (breaking force) of the fruit. In the fruit storage boxes only one part of the fruit was in contact with other fruits or box walls. As a result, by using force measurement at the contact point and contact surface, the maximum contact stress was calculated using the contact stress theory (Figure 1). This theory reflects the following principles.

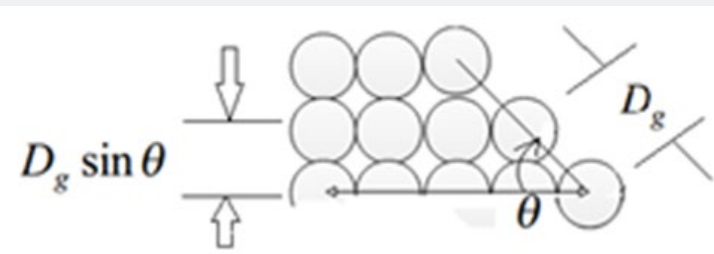

Figure 1: The parallel arrangement of fruits relative to each other.

The contact of fruits together was considered on a line that formed angle $\theta$ with the horizon line. In this model, the angle $\theta$ depended on the diameter of the fruits (Dg) and the number of fruits per unit volume $(\mathrm{N})$. The relationship between these three parameters was in the form of relation (1) [7].

$$
N=\frac{1}{4 D_{g}^{3} \cos ^{2} \theta \sin \theta}
$$

The number of fruits per unit volume was obtained from the ratio of mass density to the mass of each fruit multiplied by its unit volume. To calculate the total force applied to one layer, a box was considered in which $\mathrm{n}$ rows of fruit are located. The upper half of each fruit is in contact with four fruits in the upper layer and the lower half is in contact with four fruits in its lower layer. So there is no force on the top half of the first row. Therefore, there was no reaction on the lower half and only the forces involved in this part have been the weight of the fruits. On the other hand, the fruits in the $\mathrm{n}$ layer, on the upper side are in contact with their higher-level fruit and on the sides are in contact with the floor and the wall of the box. As a result, the total force exerted by the upper layers was calculated using relation (2) [7].

$$
F=n \times w
$$

In this relation, $\mathrm{n}$ is the rows of fruit, $\mathrm{F}$ is the total force on the fruit in the last layer and $\mathrm{W}$ is the average weight of the fruit.

Since, the closer to the bottom of the box, the static force enters the fruit in the upper end layers is more, by calculating this amount of force, the design of the standard box height for storing the cherry fruit is addressed. The amount of force on the fruit was considered to be the minimum breaking force and thus, the fruit loading was determined by the HTE-series-H45 K Model in mechanical experiments. Depth of box (h) was calculated from relation (3) [7].

$$
h=n D_{g} \sin \theta
$$

In this relation, $\mathrm{h}$ is the box height $(\mathrm{cm}), \mathrm{n}$ is the number of fruit layers, Dg is the geometric mean diameter $(\mathrm{cm})$, and $\theta$ is the angle of the fruits relative to each other inside the box. The measurement of the three main vertical dimensions of the cherry fruit, length (a) (mm), width (b) (mm) and thickness (c) (mm) was determined using a digital caliper with a measurement accuracy of $0.01(\mathrm{~mm})$. The geometric mean diameter of the fruit $(\mathrm{Dg})(\mathrm{mm})$ and the spherical coefficient $(\psi)$ (dimensionless) were calculated using the following relationships [6]

$$
\begin{aligned}
& D_{g}=(a b c)^{1 / 3 / a} \\
& D_{g}=(a b c)^{1 / 3}
\end{aligned}
$$

The mass of the samples was measured with a measurement accuracy of $0.01 \mathrm{~g}(\mathrm{mt})$ by the digital scale. To measure the density of samples (Pb), an empty cylinder with a given volume was filled with fruit, and by the division of the mass of the fruit into volume, density was obtained.

$$
\rho_{b}=\frac{m_{b}}{V_{b}}
$$

In this relation, the mass (mb) was expressed in terms of $(\mathrm{g})$ and the volume of cylinder $(\mathrm{Vb})$ in terms of $\left(\mathrm{cm}^{3}\right)$. The hardness of the fruit was measured by a biological measuring device at loading speed (0.1) (mm. $\left.\mathrm{min}^{-1}\right)$.

\section{Results and Discussion}

The length, width, thickness, geometric mean diameter, spherical coefficient, mass density, and mass of the cherry fruit sample were, $12.65(\mathrm{~mm}), 14.33(\mathrm{~mm}), 11.46(\mathrm{~mm}), 12.76(\mathrm{~mm})$, $0.89,0.401\left({\mathrm{~g} . \mathrm{cm}^{-3}}^{-3}, 2.91(\mathrm{~g})\right.$, and also the hardness of the fruit was calculated $1.98(\mathrm{~N})$.

\section{Conclusion}

Crushing force of cherry is equal to $1.98 \mathrm{~N}$, which is equal to 40 layers of fruit. It is therefore recommended to use boxes with a maximum height of $30 \mathrm{~cm}$ to transport and store cherry fruit, so that the fruit of the cherry, during storage and transport, do not break due to mass weight.

\section{References}

1. Tavakoli T (2004) (Mechanics of Agricultural Products) Compilation of Citechi. J Tarbiat Modares University Press, Iran pp. 530.

2. Jamali M (2015) Statistics and information about cherry fruit. Ministry of Agricultural department.

3. Hasebawi E, Minaee S, Kazemi Sh (2009) Designing a suitable packing box for reducing cherry fruit waste. Fourth National Conference on Agricultural Products Waste.

4. Hacıseferogullari H, Gezer I, Ozcan MM, Bayram MA (2007) Postharvest chemical and physical-mechanical properties of some apricot varieties cultivated in Turkey. Journal of Food Engineering 79: 364-373.

5. Kilickan A, Guner M (2008) Physical properties and mechanical behavior of olive fruits (Olea europaea $L$.) under compression loading. Journal of Food Engineering 87(2): 222-228.

6. Mohsenin NN (1978) Physical properties of plant and animal materials. Gordon and Breach, New York, USA.

7. Stroshine R, Hamann D (1994) Physical properties of agricultural material and food products. West Lafayette: Dept of Agricultural Engineering Purdue University, USA. 
This work is licensed under Creative Commons Attribution 4.0 License DOI: 10.19080/ARTOAJ.2018.16.555996
Your next submission with Juniper Publishers will reach you the below assets

- Quality Editorial service

- Swift Peer Review

- Reprints availability

- E-prints Service

- Manuscript Podcast for convenient understanding

- Global attainment for your research

- Manuscript accessibility in different formats

( Pdf, E-pub, Full Text, Audio)

- Unceasing customer service

Track the below URL for one-step submission https://juniperpublishers.com/online-submission.php 